\title{
Peternak Ayam Ras Petelur
}

\section{Laying Hen Farmer}

\section{Muhammad Nur ${ }^{1}$ \\ Mustam ${ }^{2}$ \\ Yudhi Dwi Hartono ${ }^{3}$ \\ Ahmad Muhlis Nuryadi ${ }^{*}$ \\ ${ }^{1}$ Department of Agribusiness, Universitas Muhammadiyah Kendari, Kendari, Southeast Sulawesi, Indonesia \\ 2Department of Management, Universitas Muhammadiyah Kendari, Kendari, Southeast Sulawesi, Indonesia \\ ${ }^{3}$ Department of Architecture, Universitas Muhammadiyah Kendari, Kendari, Southeast Sulawesi, Indonesia}

email:

muhlis.nuryadi@umkendari.ac.id

\section{Kata Kunci}

Al-Barkah

Ayam ternak

Desa Alebo

Keywords:

Al-Barkah

Chicken livestock

Alebo village

Received: November 2020

Accepted: March 2021

Published: June 2021

\begin{abstract}
Abstrak
Usaha Kecil dan Menengah (UKM) merupakan salah satu pilar kekuatan ekonomi masyarakat karena dalam pengelolaanya melibatkan masyarakat secara langsung, baik dalam menyediakan sarana produksi, tenaga kerja maupun dalam rantai pemasarannya. Namun demikian tidak sedikit UKM harus gagal ditengah jalan ataupun tidak mampu berkembangan, kondisi ini juga terjadi pada UKM Peternakan Ayam Ras Al-Barkah. Tujuan pelaksanaan program ini adalah peningkatan kapasitas usaha baik dari aspek produksi maupun aspek manajemen pada usaha ternak ayam ras petelur Al-Barkah. Metode yang akan digunakan dalam mengatasi permasalahan dan mencapai tujuan adalah dengan memberikan pelatihan, bimbingan, dan aplikasi ipteks secara langsung. Semua kegiatan dilakukan bersama oleh pemilik dan karyawan UKM Mitra dengan dibimbing oleh tim pelaksana. Hasil kegiatan adalah : (1) Dimilikinya pemahaman dan kemampuan mitra dalam melakukan perencanaan usaha; (2) Dimilikinya kemampuan dalam melakukan efektifitas dan efisiensi usaha; (3) Meningkatnya pemahanan akan pentingya keteraturan dalam proses usaha ternak; (4) Dipahaminya pentingnya kebersihan dan sanitasi kandang; dan (5) Meningkatnya kesehatan ayam, produksi telur dan pendapatan peternak. Kesimpulan dari hasil pelaksanaan program adalah usaha ternak ayam ras petelur AlBarkah mengalami peningkatan produksi sebesar 15\% dan peningkatan efisiensi usaha $12 \%$ sebagai dampak dari perbaikan aspek produksi dan manajemen usaha.
\end{abstract}

\begin{abstract}
Small and Medium Enterprises (SMEs) are one of the economic strength pillars of the community because their management involves the community directly, both in providing production facilities, labors, and its marketing chain. However, some SMEs failed in the middle of their business road or are unable to develop. This condition also occurs in SME of Al-Barkah Laying HenFarm. The purpose of implementing this program is to increase business capacity both from the production and management aspects of the Al-Barkah layer chicken business. The method used in overcoming these problems and achieving goals is by providing direct training, guidance, and application of science and technology. All activities were carried out jointly by the owners and employees of UKM Partners, guided by the implementation team. After implementing the program, the SME partner now: (1) understands and can conduct business planning; (2) can carry out business effectiveness and efficiency; (3) can increase understanding of the importance of order in the livestock business process; (4) Understands the importance of hygiene and cage sanitation; and (5) can increase the chicken health, egg production, and farmer income. The conclusion from the program implementation is that the Al-Barkah layer chicken business has increased production by $15 \%$ and an increase in business efficiency by $12 \%$ as a result of improvements in production and business management aspects.
\end{abstract}




\section{PENDAHULUAN}

Usaha Kecil dan Menengah (UKM) Al-Barkah secara resmi menjadi UKM dalam bentuk usaha perorangan pada tanggal 16 November tahun 2005 sesuai penetapan Pemerintah Daerah Kabupaten Konawe Selatan nomor 510/94/XI/2005, Surat Izin Tempat Usaha (SITU) Nomor 517/542/XI/2005 dan Surat Izin Usaha Perdagangan Kecil (SIUP) Nomor 510/97/XI/2005. Usaha peternakan Al-Barkah pernah mengalami masa puncak populasi yaitu pada tahun 2009 dan awal 2010 dimana populasi ayamnya mencapai 5.000 ekor, hal ini juga tampak saat tim pelaksana mengunjungi lokasi peternakan dimana masih banyak bekas-bekas bangunan kandang dan peralatan kandang yang tersimpan. Namun pada akhir 2010 peternakan AlBarkah mengalami wabah penyakit sehingga hampir semua ayam miliknya mati. Selama 2 tahun usaha peternakan ini tidak beroperasi, pada tahun 2013 usaha ini bangkit kembali dan saat ini populasi ternak mencapai 2.000 ekor (2 kandang). Menurut pemilik seharusnya ayamnya sudah 3 kandang namun tahun lalu ayamnya yang baru berumur 20 hari terkena penyakit dan hanya tersisa sekitar $15 \%$ dari 1.300 ekor.

Berdasarkan pada Gambar 1 dan Gambar 2, terlihat bahwa manajemen tata kelola kandang dan lingkungan kandang ternak ayam belum dijalankan dengan baik sehingga dapat dipastikan akan mempengaruhi kesehatan dan produksi ayam. Gambar tersebut memperlihatkan kondisi peternakan yang kurang memperhatikan sanitasi kandang dimana kotoran ayam bercampur dengan air yang tentunya akan menimbulkan bau yang sangat tidak sedap, mengangkat amoniak ke udara dan akan menimbulkan berbagai macam penyakit, demikian juga lingkungan sekitar kandang yang sangat rimbun oleh belukar dan rumput liar (Linggotu et al., 2016; Olivianti et al., 2016).

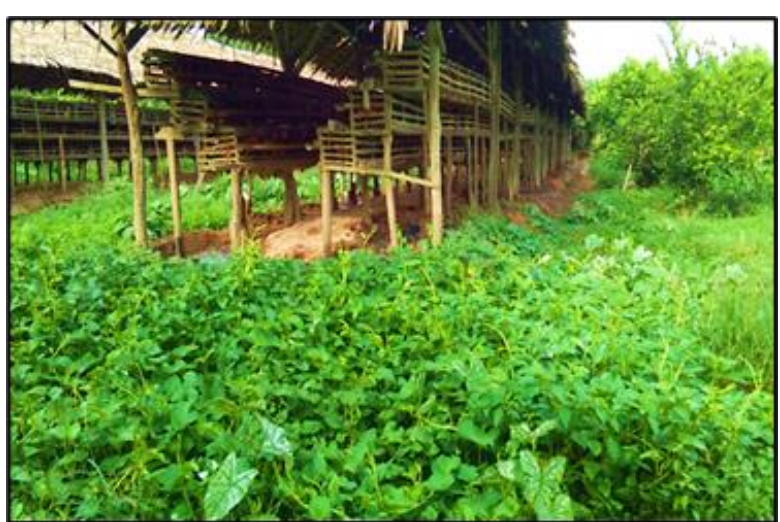

Gambar 1. Lingkungan Kandang yang di Penuhi Rumput Belukar

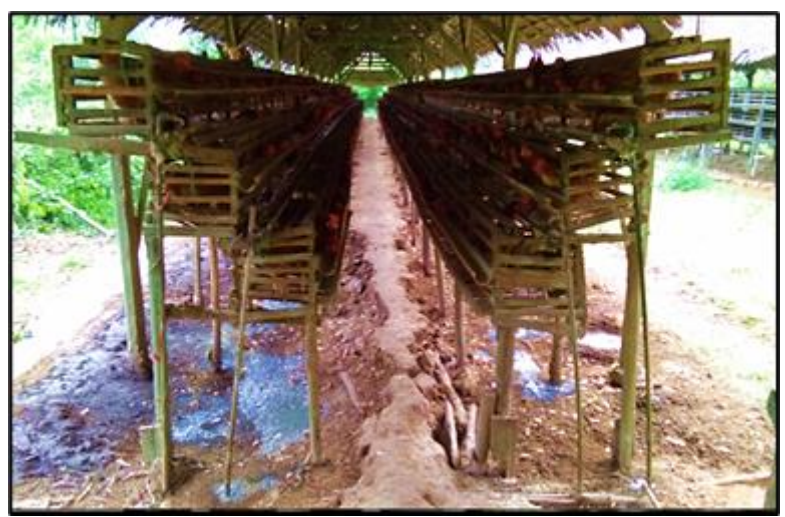

Gambar 2. Lantai Kandang yang Basah dan Berlubang

Hasil diskusi dengan Petugas Penyuluh Lapangan (PPL) Peternakan Kecamatan Konda dan Kepala Desa Alebo (Abdul Manad Zani) dan melalui pengamatan secara langsung oleh tim tergambar bahwa kegiatan UKM calon mitra sangat terkendala dengan kualitas SDM, modal, manajemen produksi, dan fasilitas penunjang kesehatan ayam. Memperhatikan kondisi tersebut maka permasalahan utama dan akan menjadi fokus pemecahan masalah adalah rendahnya kemampuan manajemen, rendahnya keterampilan budidaya, rendahnya produktifitas, dan tidak adanya sistem biosekuriti ternak termasuk pengolahan kotoran ternak agar tidak menganggu kesehatan ternak serta masih rendahnya skala produksi sehingga efisiensi usaha sulit tercapai. Semua permasalan tesebut dapat teratasi jika terjadi peningkatan kualitas SDM dan perubahan atau perbaikan perilaku yang dimulai dengan pemahaman 
akan adanya persepsi untuk memperbaiki kualitas diri dalam beternak yang baik (Ashary, 2016). Menurut Sari dan Herdiyana (2017), faktor yang menentukan tingkat keberhasilan didalam usaha budiaya ayam adalah manajemen pemeliharaan, manajemen pakan, manajemen vaksinasi dan manajemen perkandangan.

Menurut Bergevoet et al. (2004), kontrol terhadap perilaku adopsi adalah keyakinan seseorang untuk dapat mengontrol dan mengendalikan perilaku akibat adopsi teknologi. Adapun skala usaha adalah jumlah ayam ras petelur yang dimiliki oleh peternak selama satu siklus produksi. Amsalu dan de Graaff (2007) juga menyatakan bahwa semakin meningkat skala usaha maka semakin meningkat pula adopsi teknologi petani dan semakin meningkat skala usaha maka adopsi teknologi serta komitmen untuk melanjutkan adopsi teknologi petani semakin meningkat pula.

Permasalahan yang dialami oleh calon mitra secara spesifik dapat diuraikan dalam dua kelompok yaitu permasalahan pada aspek produksi dan permasalahan pada aspek manajemen. Uraian masing-masing permasalahan tersebut adalah minimnya sanitasi dan biosecurity gudang pakan dan kandang, belum diketahuinya penanganan day old chicken (DOC) yang tepat, kurang dipahaminya formulasi ransum, tidak dilakukannya pengelolaan kotorang ternak secara tepat, rendahnya produktivitas usaha, minimnya pemahanan mitra dalam manajemen usaha, manajemen keuangan dan administrasi usaha, belum adanya sistem perencanaan usaha yang baik, dan belum terbangunnya sistem kemitraan terutama dalam penyediaan bahan baku dan mengakses permodalan.

\section{METODOLOGI}

Peralatan yang digunakan atau dibutuhkan dalam penyelesaian permasalahan mitra diantaranya adalah tempat air minum ayam otomatis, pemanas DOC elektrik, tandon air, mesin air, seng polos, scopan dan cangkul. Bahan-bahan yang digunakan dalam pelaksanaan program adalah terpal, EM4 sebagai enzim pengurai kotoran ternak, gas elpiji, sekam padi dan DOC.

Metode pelaksanaan kegiatan ditunjukkan dengan tahapan dan langkah-langkah dalam mengatasi permasalahan-permasalahan dalam bidang produksi dan manajemen. Secara rinci tahapan-tahapan dalam menyelesaikan permasalahan mitra adalah sebagai berikut:

1. Permasalahan Bidang Produksi

Metode yang dilakukan dalam menyelesaikan permasalahan dalam bidang produksi adalah sebagai berikut:

a. Dilakukannya penyuluhan intensif baik secara berkelompok maupun sendiri-sendiri, baik secara formal, informal maupun situasional tentang keterampilan dalam usaha ternak ayam ras petelur. Penyuluhan dilakukan baik pada kegiatan yang telah disepakati untuk dilaksanakan seperti keterampilan dalam pengelolalan pakan baik dari sistem penggudangan atau sirkulasi pakan maupun formulasi pakan, penanganan DOC dan pembesaran, penanganan saat proses produksi pada kandang produksi, penanganan kotoran ternak dan pengelolaan biosekuriti kandang

b. Melakukan praktek yang dilakukan oleh anggota mitra dengan bimbingan langsung oleh tim pelaksana dibantu oleh tenaga lapangan.

2. Pemasalahan Bidang Manajemen

Metode yang dilakukan dalam menyelesaikan permasalahan dalam bidang manajemen adalah sebagai berikut:

a. Dilakukannya pelatihan intensif baik secara bersama maupun sendiri-sendiri, baik secara 
formal maupun situasional tentang pengelolaan manajemen usaha, membuat daftar rencana kegiatan, pengelolaan keuangan, melakukan pembukuan kegiatan, manajemen usaha, dan manajemen perencanaan dan evaluasi usaha.

b. Kelompok mitra melakukan praktek pengelolaan usaha pada usaha yang sedang dilakukan, membuat daftar perencanaan kerja, melakukan pencatatan atas semua kegiatan, dan melakukan evaluasi internal.

\section{HASIL DAN PEMBAHASAN}

Hasil yang telah dicapai oleh tim bersama mitra diuraikan atas dua aspek yaitu aspek produksi dan aspek manajemen. Hasil pelaksanaan dan kegiatan yang telah dilakanakan tim pelaksana bersama mitra dari aspek produksi diantaranya adalah meliputi proses penanganan DOC, penanganan proses pembesaran, penyiapan kandang pembesaran dan penyediaan fasilitas penunjang. Uraian pelaksanaan program dari aspek produksi adalah sebagai berikut:

\section{Penanganan DOC}

Day old chicken (DOC) adalah ayam ras petelur yang berumur 1 hari. DOC mitra sebagaimana semua peternak ayam di Provinsi Sulawesi Tenggara memperoleh dari luar daerah yaitu Makassar atau Surabaya. Penanganan DOC bagi keberhasilan peternakan ayam sangat penting. Penanganan yang kurang tepat dapat berakibat fatal (Simanjuntak, 2018).

Penanganan DOC yang dilakukan diantaranya adalah penyiapan tempat yang ideal bagi DOC. Introduksi ipteks yang diberikan adalah pembuatan seng pengaman keliling ruang kandang dengan bentuk lingkaran. Disamping mencegah adanya udara dingin yang masuk dari celah dinding juga metode lingkaran membuat ayam akan merasa luas karena posisi ruangan tidak memiliki sudut. Hal ini juga menghindarkan terjadinya pengerombolan ayam pada sudut ruangan (Pratitis et al., 2018).

Selain model ruang berbentuk lingkaran, pemanas yang digunakan tidak lagi berupa tungku arang yang sangat tidak praktis dan efektif (Soolany, 2017). Namun mengunakan pemanas otomatis dengan bahan bakar elpiji sehingga praktis, bersih dan efektif. Pemanasan akan diberikan seara terus menerus hingga ayam berumur 15 hari dan akan diberikan hingga 30 hari hanya pada malam hari atau cuaca siang hari terjadi hujan (Nadzir et al., 2015). Berikut adalah proses penanganan DOC yang dilakukan mitra dengan arahan tim pelaksana.

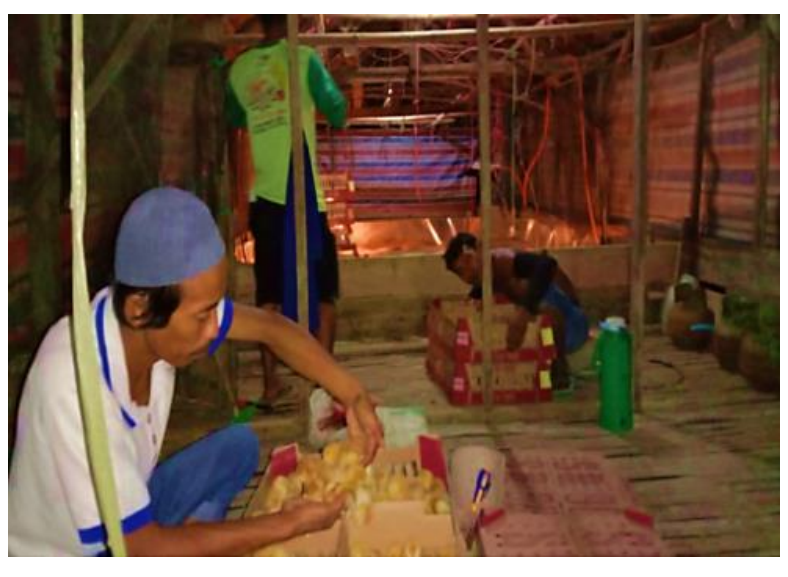

Gambar 3. Persiapan dan penanganan DOC

2. Perawatan proses pembesaran

Setelah proses penanganan DOC, langkah selanjutnya adalah penanganan proses pembesaran. Aspek yang sering menjadi kendala mitra adalah tingkat stress yang tinggi yang dialami ayam karena karyawan harus sering masuk kandang untuk memberi makan dan minum jika masih mengunakan tempat minum manual. Selain hal tersebut, metode ini sangat tidak efisien bagi tenaga kerja dan juga memiliki resiko akan kehabisan air minum jika suhu udara tinggi (Putra et al., 2018; Setiawati et al., 2016).

Introduksi yang diberikan untuk mengatasi masalah 
tersebut adalah dengan pengadaan sekaligus memberikan pelatihan penggunaan tempat air minum otomatis. Berikut adalah proses penyerahan dan pemasangan tempat air minum otomatis. Selain itu juga dilakukan pengadaan tower air karena salah satu kendala adalah seringnya mati listrik sehingga terkadang ayam harus terlambat memperoleh air minum.

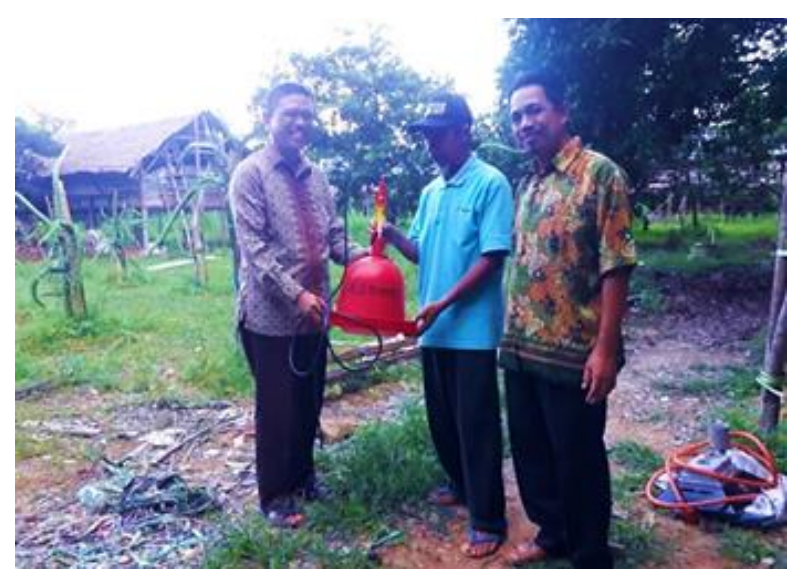

Gambar 4. Penyerahan Tempat Minum Otomatis

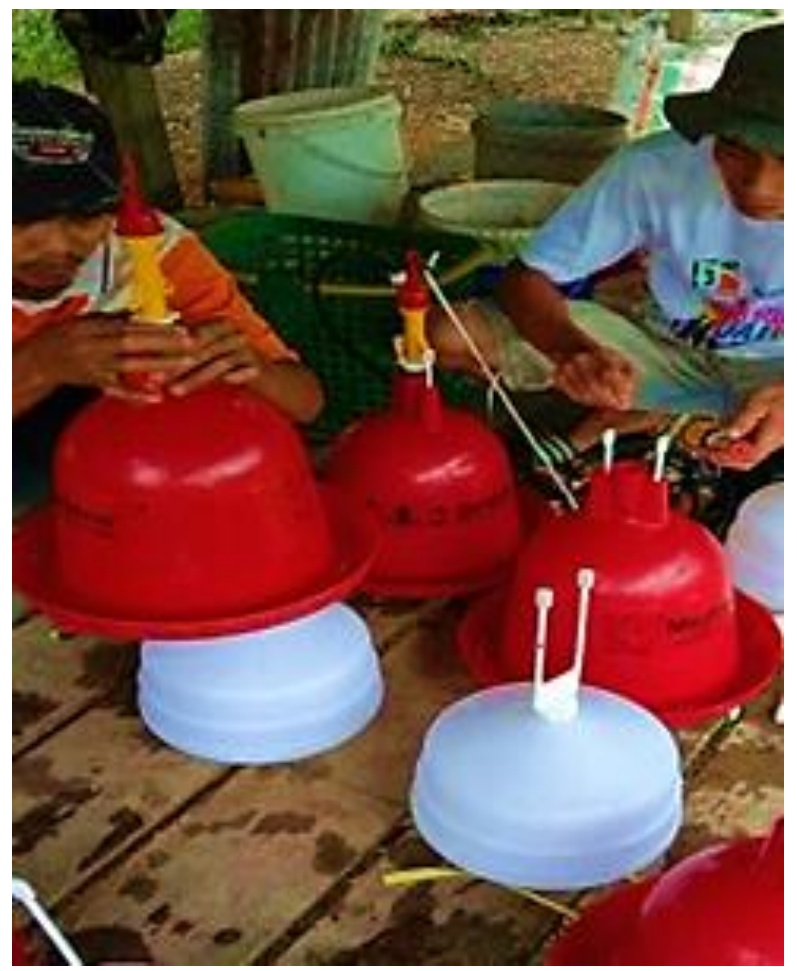

Gambar 5. Perakitan Tempat Minum Otomatis

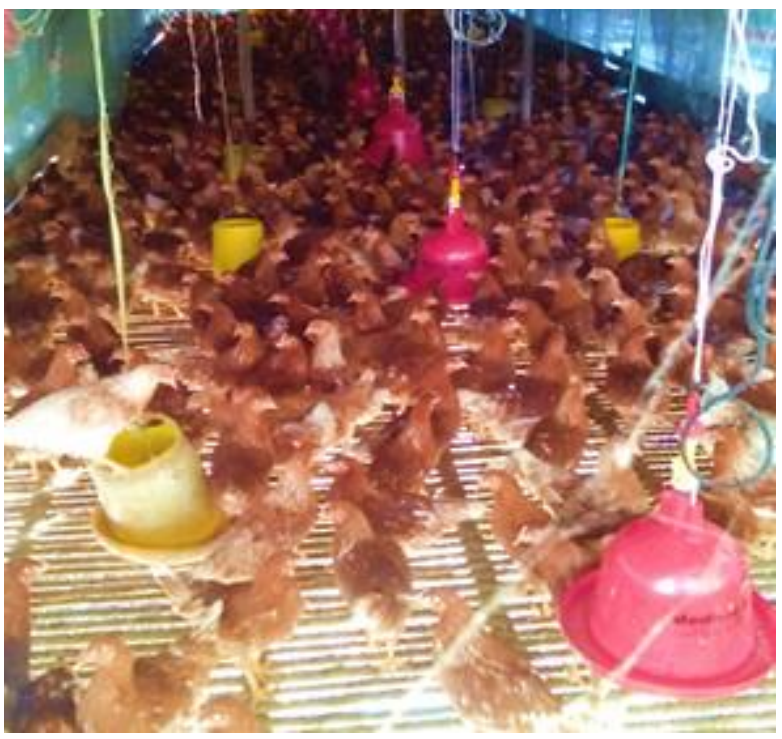

Gambar 6. Pemanfaatan Tempat Minum Otomatis

3. Penyiapan kandang produksi

Kandang produksi atau kandang baterai adalah kandang yang diperuntukkan untuk ayam dalam proses produksi. Kandang dibuat dengan atap seng agar tahan serta mengunakan lantai papan agar tidak terjadi penyebaran debu saat karyawan kandang memberi makan ayam. Kontruksi kandang ini dibuat dengan lantai padat, kemiringan yang ideal dan memudahkan roses pembersihan. Hal ini sangat penting karena kebersihan dan sanitasi kandang sangat mempengaruhi kesehatan ayam. Dahlan dan Hudi (2011) menyatakan bahwa sanitasi kandang ayam perlu dilakukan dengan konsisten. Berikut adalah dokumentasi proses pembuatan kandang produksi yang dilakukan mitra.

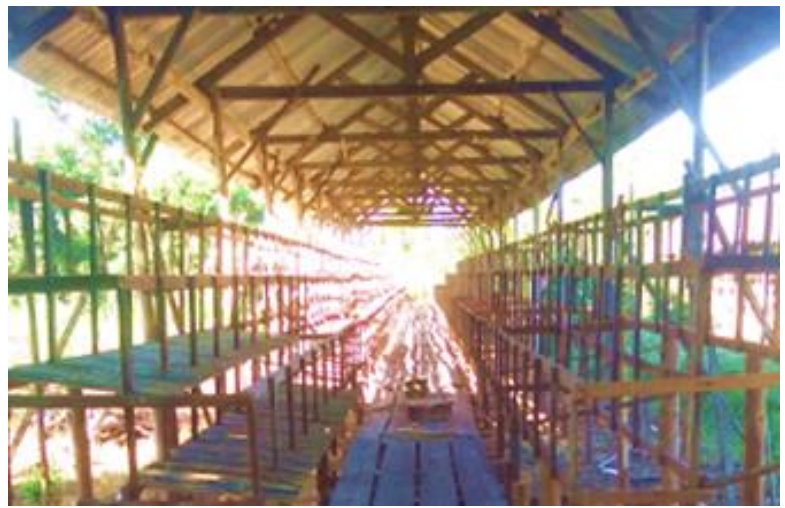

Gambar 7. Proses Pembuatan kandang Baterai (Kandang Produksi) 
4. Penyediaan Fasilitas Penunjang

Selain proses penanganan DOC dan pemelihaan dalam proses pembesaran serta penyiapan kandang produksi, program juga memberikan introduksi fasilitas pemanas untuk penghangat DOC sebagaimana uraian sebelumnya.

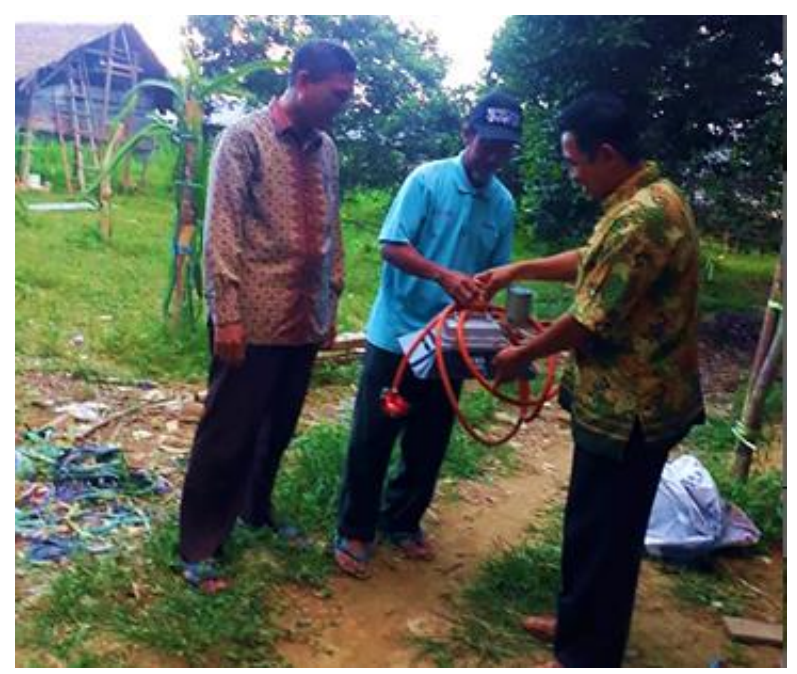

Gambar 8. Penyerahan Alat Pemanas DOC

\section{KESIMPULAN}

Dari hasil kegiatan pengabdian yang telah dilakukan, dapat ditarik kesimpulan bahwa telah dimilikinya pemahaman dan kemampuan mitra dalam melakukan perencanaan usaha, melakukan efektifitas dan efisiensi usaha, meningkatnya pemahaman akan pentingnya keteraturan dalam proses usaha ternak, dipahaminya pentingnya kebersihan dan sanitasi kandang, meningkatnya kesehatan ayam, produksi telur dan pendapatan peternak, serta terjadi peningkatan produksi sebesar $15 \%$ dan efisiensi usaha sebesar $12 \%$.

\section{UCAPAN TERIMA KASIH}

Artikel ini merupakan hasil pelaksanaan program Hibah Pengabdian yang dibiayai oleh Kementerian Riset, Teknologi dan Pendidikan Tinggi dalam Hibah Program kepada Masyarakat pada Skema Program Kemitraan Masyarakat (PKM) tahun 2019. Terimakasih penulis ucapkan kepada mitra, Dekan Fakultas Pertanian, Rektor Universitas Muhammadiyah Kendari dan Kementerian Riset, Teknologi dan Pendidikan Tinggi Republik Indonesia.

\section{REFERENSI}

Amsalu, A., de Graaff, J. 2007. Determinants of adoption and continued use of stone terraces for soil and water conservation in an Ethiopian highland watershed. Ecological Economics. 61(2-3):294302. https://doi.org/10.1016/j.ecolecon.2006.01.01 4

Ashary, L. 2016. Pengaruh Praktik Manajemen Sumber Daya Manusia Terhadap Produktivitas Karyawan Peternak Ayam Potong PT. Mitra Gemuk Bersama (MGB) di Kabupaten Jember. Jurnal Ekonomi dan Bisnis Growth. 14(2):72-82.

Bergevoet, R.H.M., Onderstejin, C.J.M., Saatkamp, H.W., van Woerkum, C.M.J., Huirne, R.B.M. 2004. Entrepreneurial behaviour of dutch dairy farmers under a milk quota system: goals, objectives and attitudes. Agricultural Systems. 80(1):1-21. https://doi.org/10.1016/j.agsy.2003.05.001

Dahlan, M., Hudi, N. 2011. Studi Manajemen Perkandangan Ayam Broiler Di Dusun Wangket Desa Kaliwates Kecamatan Kembangbahu Kabupaten Lamongan. Jurnal Ternak. 2(1):24-29.

Linggotu, L.O., Paputungan, U., Polii, B. 2016. Pengelolaan Limbah Kotoran Ternak Dalam Upaya Pencegahan Pencemaran Lingkungan Di Kota Kotamobagu. Zootec. 36(1):226-237. https://doi.org/10.35792/zot.36.1.2016.10535

Nadzir, Tusi, A., Haryanto, A. 2015. Design Evaluation of Broiler House in Rejo Binangun, Kecamatan Raman Utara, Kabupaten Lampung Timur. Jurnal Teknik Pertanian Lampung. 4(4):255-266.

Olivianti, A., Abidjulu, J., Koleangan, H. 2016. Dampak Limbah Peternakan Ayam Terhadap Kualitas Air Sungai Sawangan Di Desa Sawangan Kecamatan Tombulu Kabupaten Minahasa. Chemistry Progress. 9(2):45-49. https://doi.org/10.35799/cp.9.2.2016.27986 
Pratitis, W, Wida E.R., Dwi, S.W. 2018. Menumbuhkan Wirausaha Melalui Program IBIKK Budidaya Ayam Kampung di Experimental Farm Jatikuwung UNS. Dian Mas: Jurnal Inovasi dan Aplikasi Ipteks. 7(1):27-34.

Putra, C.G.N., Maulana, R., Fitriyah, H. 2018. Otomasi Kandang Dalam Rangka Meminimalisir Heat Stress Pada Ayam Broiler Dengan Metode Naive Bayes. JPTIIK (Jurnal Pengembangan Teknologi Informasi dan Ilmu Komputer). 2(1):387394.

Sari, M.L., Herdiyana, M. 2017. Manajemen Perkandangan Ayam Petelur Afkir Di Breeding Farm PT. Vista Agung Kencana Farm 2 Desa Talang Taling Kecamatan Gelumbang Muara Enim. Jurnal Peternakan Sriwijaya. 6(2):100-106. https://doi.org/10.33230/JPS.6.2.2017.5085

Setiawati, T., Afnan, R., Ulupi, N. 2016. Performa Produksi dan Kualitas Telur Ayam Petelur pada Sistem Litter dan Cage dengan Suhu Kandang Berbeda. Jurnal Ilmu Produksi dan Teknologi Hasil Peternakan. 4(1):197-203.

Simanjuntak, M.C. 2018. Analisis Usaha Ternak Ayam Broiler Di Peternakan Ayam Selama Satu Kali Masa Produksi. Jurnal Fapertanak: Jurnal Pertanian dan Peternakan. 3(1):60-81.

Soolany, C. Analisis Kehilangan Panas Pada Proses Produksi Arang Tempurung Kelapa Dengan Drum Kiln. Jurnal Teknologi. 10(2):121-127. 